\title{
Damages, Pathologies and Repair of a Bay of South Facade Villa Zerbi Reggio Calabria Italy
}

\author{
Shaikh M. Javaria \\ Master Erasmus Mundus Emdireb European Master in Diagnosis and Repair of Buildings Università Mediterranea Di Reggio Calabria \\ $\mathrm{PhD}$ Scholar Hanyang University, South Korea \\ *Corresponding Author: javeria@hanyang.ac.kr
}

Copyright (C) 2013 Horizon Research Publishing All rights reserved.

\begin{abstract}
This research presents the diagnosis, definition of pathology and damages and possible conservation intervention of a selected portion of Genose Villa Zerbi in Reggio Calabria which is been converted into a museum. It focuses on visual and structural intervention and integrity of the new with old, on the basis of diagnosis of selected component of the building and provides analysis based on the field study. Furthermore, the clear intension has been that the intervention should be reversible that is; to save the building from further deterioration, and to highlight clearly the difference to the future scientist, so that if any new technology is discovered, offering a better solution of the same problem, the present solution can be replaced.
\end{abstract}

Keywords Low Viscosity, Sufficient Workability, Low Shrinkage, Corrosion Proof, Adhesion to Crack Edges, High Durability and Strength

\section{Introduction}

The Villa Genoese Zerbi in Reggio Calabria beach front was constructed right after 1908 server earth quack; it is designed in a Venetian style, hence it is a diverse plan type from the neighbours, made of prefabricated material, assembled on site.

The main purpose of this building was to serve as a private residence. The building site has irregular plan with a main compartment of rectangular plan around a square court and a bigger $L$ shaped court with an attached wing. It is made up of two levels, the entrance to the compound from west leads into the entrance foyer leading to the main hallway on the ground floor into working, praying quarters on the right. The main stairs from the entrance foyer leads to upper level which is sleeping quarters.

The building is currently undergoing major restoration and renovation program to some parts of its floors. Major part of this rehabilitation project is the conversion of existing floors into an art gallery and museum.

\subsection{Description from the Materials}

The building is constructed with clay bricks, concrete and wood. External walls are painted; the floor is made of concrete and timber floor on the first floor level, whereas the roof has terra cotta tiles. The Internal finishes are of white washed paint on brick walls and tile floors.

\subsection{Objective}

To provide a detailed diagnosis of the selected portion of the building and to propose an intervention plan on the basis of a complete diagnosis providing the type of damages along with the solution. Moreover to propose a new design of reinforcing precast system, which should be visually compatible with the present system, learning form the damages caused, and applying that knowledge for the betterment of the new technique.

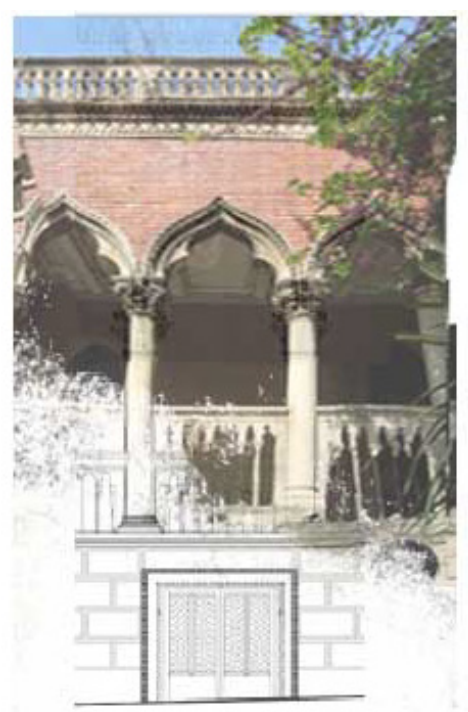

Figure 1. How the villa is situation very near the sea.

\subsection{Scope of Research}

In order to carefully identify the causes of the defects, a 
critical survey is done to identify the accuracy of the defects; the techniques used are, visual inspection and non destructive tests.

\subsection{Research Strategy}

The diagnosis and intervention process carried out using qualitative aspects, inclusive of observation (visual), discussion with the experts, investigation on the Convent of Santa Clara in Carmona using camera, sketches and drawings, tape measure and soft ware's.

\section{Literature Review}

The major point of conservation from the different Charts of conservation of Europe is analysed. Since the new buildings of today will be the heritage of tomorrow, every effort must be made to ensure that contemporary architecture is of a high quality. (Page one CONGRESS ON THE EUROPEAN ARCHITECTURAL HERITAGE 21 - 25 October 1975 The Declaration of Amsterdam)Unless a new policy of protection and integrated conservation is urgently implemented, our society will shortly find itself obliged to give up the heritage of buildings and sites which form its traditional environment. (Page three CONGRESS ON THE EUROPEAN ARCHITECTURAL HERITAGE 21 - 25 October 1975 The Declaration of Amsterdam)

\subsection{Integrated Conservation Averts these Dangers}

Integrated conservation is achieved by the application of sensitive restoration techniques and the correct choice of appropriate functions. It should be noted that integrated conservation does not rule out the introduction of modern architecture into areas containing old buildings provided that the existing context, proportions, forms, sizes and scale are fully respected and traditional materials are used. (Page 3 European Charter of the Architectural Heritage Adopted by the Council of Europe, October 1975)

\subsection{The Technique of Conservation}

In the case of ruins, scrupulous conservation is necessary, and steps should be taken to reinstate any original fragments that may be recovered (anastylosis), whenever this is possible; the new materials used for this purpose should in all cases be recognisable. (The Athens Charter for the Restoration of Historic Monuments Adopted at the First International Congress of Architects and Technicians of Historic Monuments, Athens 1931)

Article 2. The conservation and restoration of monuments must have recourse to all the sciences and techniques which can contribute to the study and safeguarding of the architectural heritage.

Aim

Article 3. The intention in conserving and restoring monuments is to safeguard them no less as works of art than as historical evidence.

\section{Conservation}

Article 4. It is essential to the conservation of monuments that they be maintained on a permanent basis. (Page 2 The Venice Charter International Charter For The

Conservation And Restoration Of Monuments And Sites) Restoration

Article 9. The process of restoration is a highly specialized operation. Its aim is to preserve and reveal the aesthetic and historic value of the monument and is based on respect for original material and authentic documents. It must stop at the point where conjecture begins, and in this case moreover any extra work which is indispensable must be distinct from the architectural composition and must bear a contemporary stamp. The restoration in any case must be preceded and followed by an archaeological and historical study of the monument.

Article 10. Where traditional techniques prove inadequate, the consolidation of a monument can be achieved by the use of any modem technique for conservation and construction, the efficacy of which has been shown by scientific data and proved by experience.

Article 12. Replacements of missing parts must integrate harmoniously with the whole, but at the same time must be distinguishable from the original so that restoration does not falsify the artistic or historic evidence. (Page 4 The Venice Charter International Charter For The Conservation And Restoration Of Monuments And Sites)

\subsection{Integrated Conservation Requires the Promotion of Methods, Techniques and Skills for Restoration and Rehabilitation}

Methods and techniques of the restoration and rehabilitation of historic complexes should be better exploited and their range developed. Specialized techniques which have been developed for the restoration of important historic complexes should be henceforth applied to the wide range of buildings and complexes of less outstanding artistic merit.

Steps should be taken to ensure that traditional building materials remain available and that traditional crafts and techniques continue to be used. Permanent maintenance of the architectural heritage, will, in the long run, obviate costly rehabilitation operations.

Every rehabilitation scheme should be studied thoroughly before it is carried out. Comprehensive documentation should be assembled about materials and techniques and an analysis of costs should be made. This documentation should be collected and housed in appropriate centres. New materials and techniques should be used only after approval by independent scientific institutions. (Page seven CONGRESS ON THE EUROPEAN ARCHITECTURAL HERITAGE 21 - 25 October 1975The Declaration of Amsterdam) 


\subsection{Diagnosis}

Diagnosis here is an inevitable investigation process carried out to this building. This is because the building is subjected to wear, tear, decay and aging process during its entire lifecycle even right after its completion and occupation stage. The diagnosis process carried out in this paper will be of the buildings ageing condition subjected to weathering, and of its structural fabric going under operation and maintenance for the change of function.

In addition, more causes of building defects can be
a) Design and specifications
b) Materials and workmanship
c) Operations and Maintenance
d) Environmental impacts
e) Ageing Process
f) Vandalism and incompatible changes
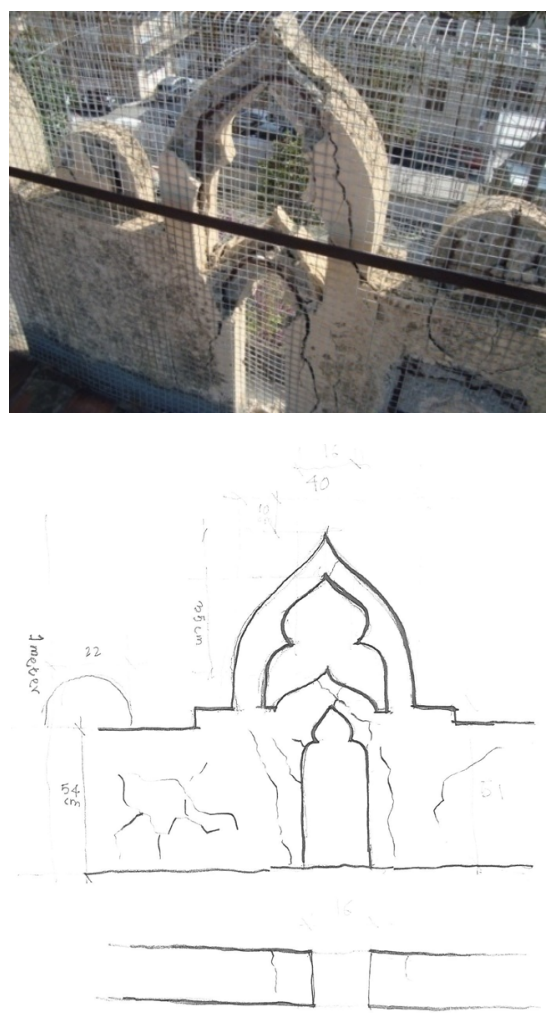

Figure 2. Pathology one Damages at the roof

\subsection{Roof Balustrade, Defining Pathology, Cracking or Fessuring}

Degradation in Figure 2 that occurs with the formation of solution of continuity in the material and may imply that the mutual displacement of the parties.

\subsection{Repair Suggestion}

Reasons of Deterioration

1. The presence of harmful substances in the atmosphere.

2. The danger of decay increased with the presence of chloride salts from the sea as shown in figure 3 .

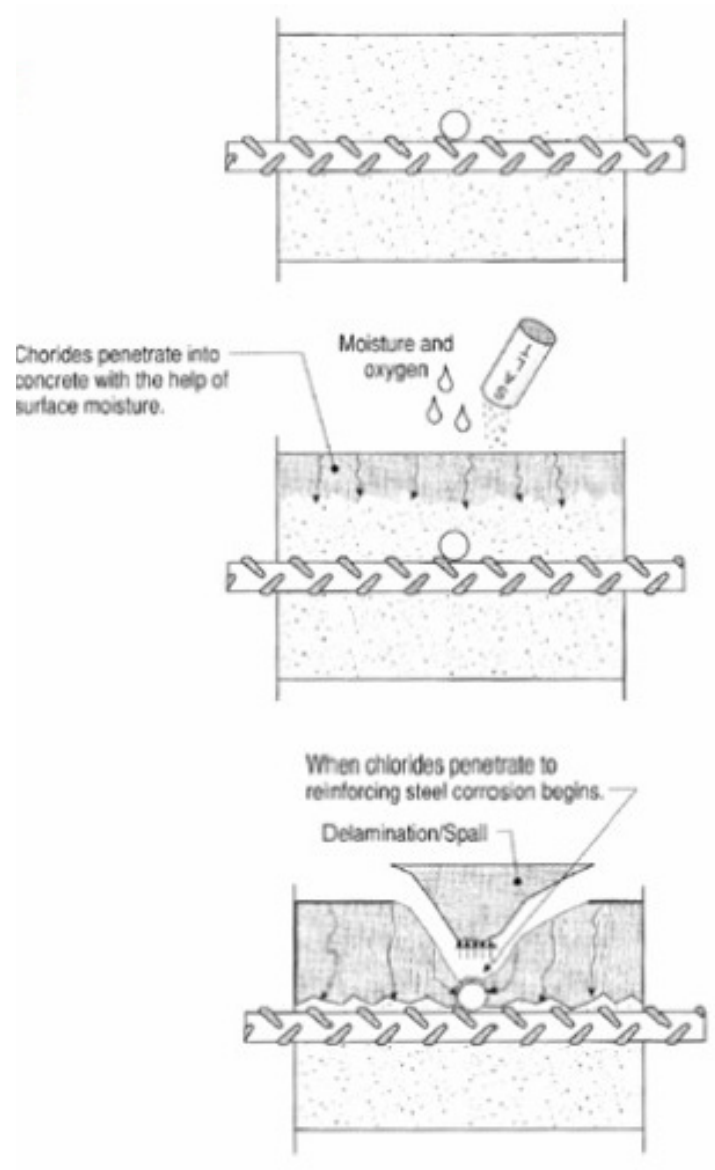

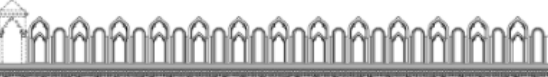

Figure 3. salt in concrete

Table 1.Cracks formation: reasons and terms of cracking

\begin{tabular}{|c|c|c|}
\hline Cracking reason & Time of cracking & Cracking risk reduction \\
\hline $\begin{array}{c}\text { 1. Fresh concrete } \\
\text { shrinkage } \\
\text { (plastic shrinkage) }\end{array}$ & $\begin{array}{c}\text { During first hours after concreting } \\
\text { 2. Heat of hydration loss }\end{array}$ & $\begin{array}{c}\text { Correct concrete proportion (water, cement content) } \\
\text { Correct preparation and placing } \\
\text { Prevention of fast drying }\end{array}$ \\
\hline
\end{tabular}


Decay process of concrete as shown in Figure 3 and 4. The above mentioned phenomenon was fast increased since there was presence of construction joints

These are the main reason for the corrosion of the material it has to be filled and the properties for cracks filling material should be as following

- Low viscosity

- Sufficient workability

- Low shrinkage

- Corrosion proof

- Adhesion to crack edges

- High durability and strength

Since the concrete used on the balustrade was casted in two stages hence the shrinkage difference also caused the damages, moreover since it was facing south façade hence maximum radiation further enhanced the process of deterioration as shown in Figure 3 and 4
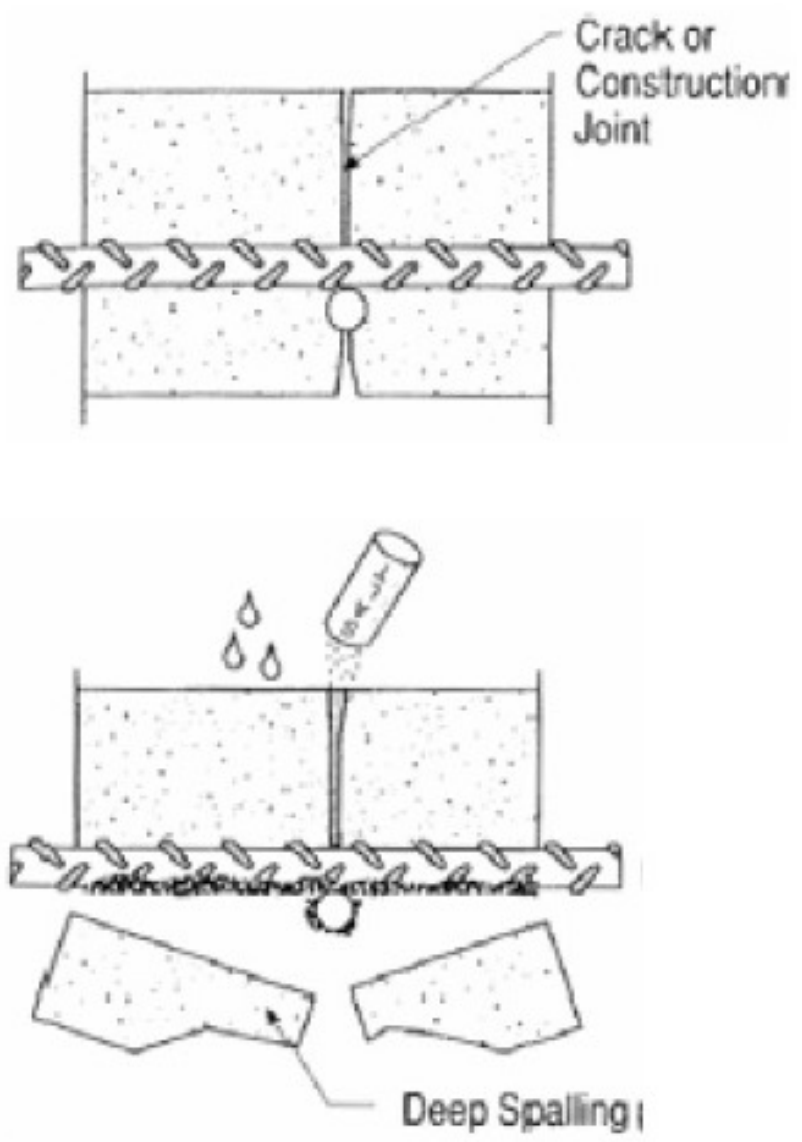

Figure 4. salt in concrete

\subsection{Type of pathology: Exfoliation}

Degradation that occurs with detachment, often followed by collapse of one or more surface layers sub-parallel between them (sheets) as shown in Figure 5.

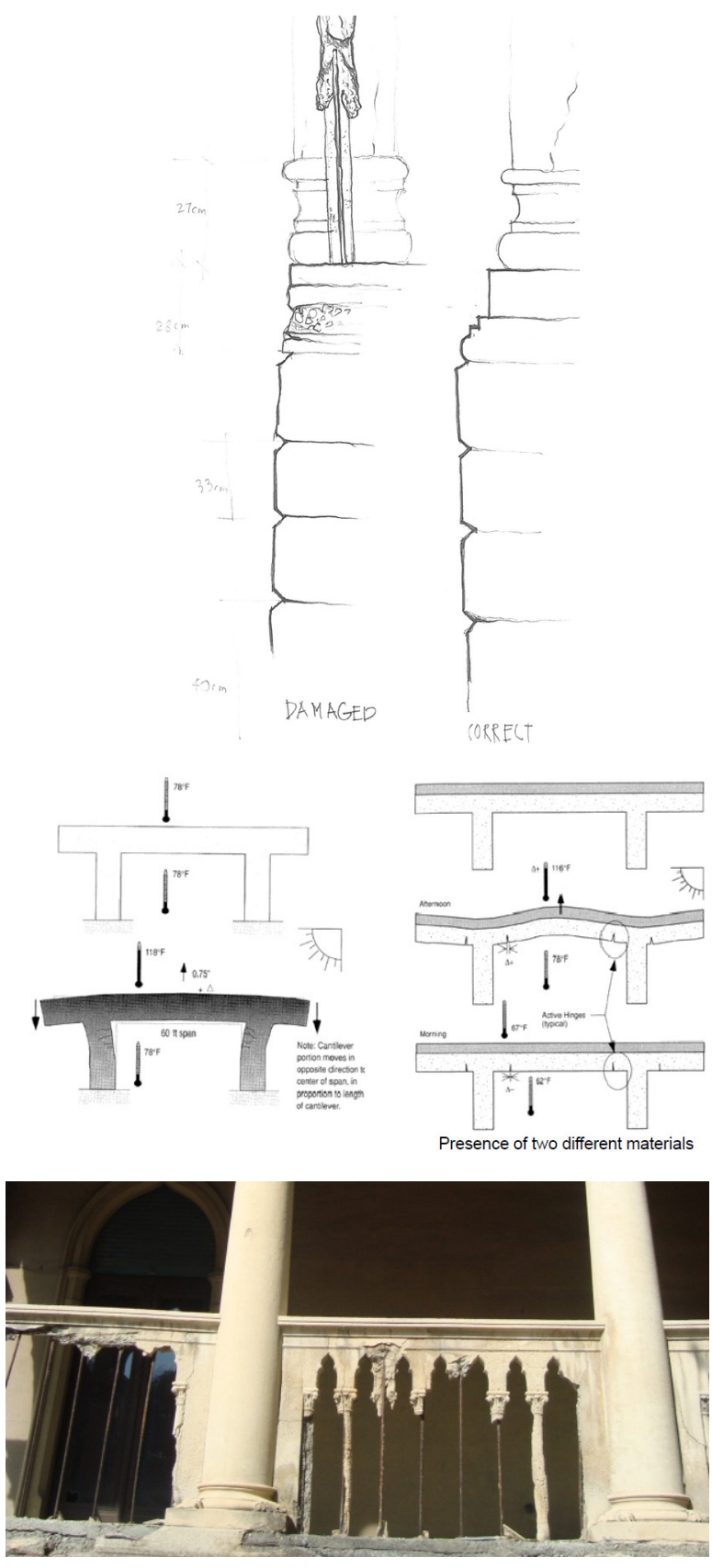

Figure 5. Exfoliation

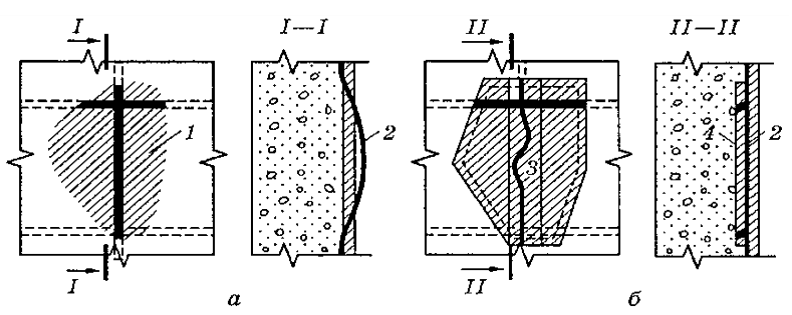

Figire 6. Repair 


\subsection{Repair Techniques}

Problem of reinforcements as shown in Figure 6 and 7
a) Exposed
b) Deformed
c) Expends
d) occurrence of gaps

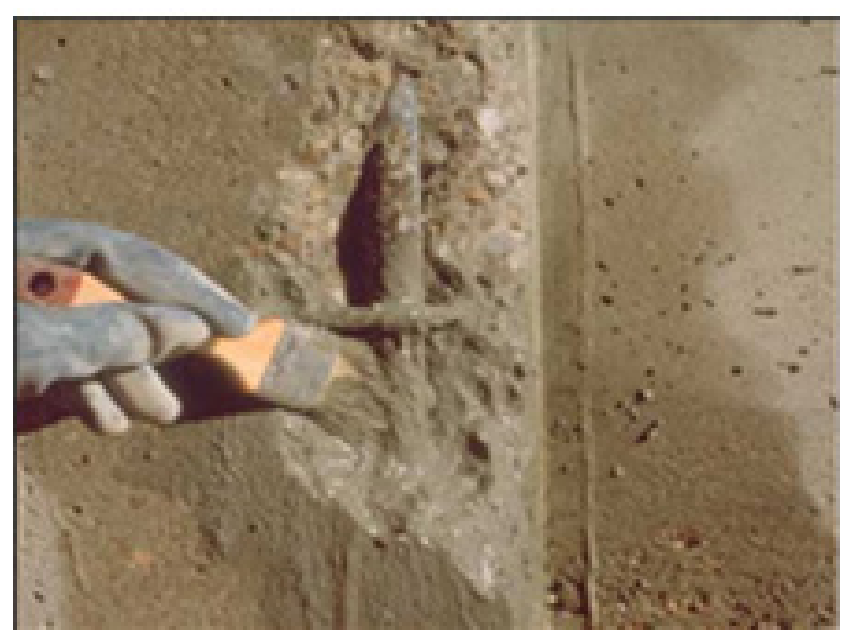

Figure 7. Covering concrete

Basic repair proceduresremoving of defective concrete layer and reinforcement opening as shown in Figure 7.

- Anticorrosive protection of the reinforcement

- Providing adhesion between "old" and "new" concrete

- Replacement of old concrete with new one where required

- Surfacing (coating) of concrete surface

- Pores coverage and protection from the environment Deterioration reasons in the material used in Villa Zerbi that is reasons of reinforced concrete damages

1. Steel corrosion $60 \%$

2. Cracks $30 \%$

3. Concrete corrosion $10 \%$

Basic reasons of deterioration

1) Impermissible coverage

2) Physical corrosion of concrete

3) Chemical corrosion of concrete

Impermissible coverage of concrete thickness depends onterms of reinforced structure performance (increase with environment aggressiveness increasing) and the diameter of reinforcing bars (increases with increasing of diameter of reinforcing bars) this varies from 1 to $5 \mathrm{~cm}$

\subsection{Erosion}

Removal of material from the surface due to processes of a different nature. When you know the causes of degradation can be also used terms such as:Erosion caused by Abrasion, Corrasion (mechanical causes), Corrosion (chemical and biological causes), Wear (anthropogenic causes) as shown in figure 8 .

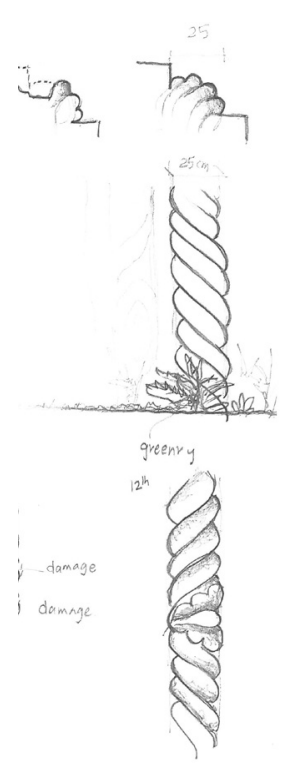

Figure 8. Erosion

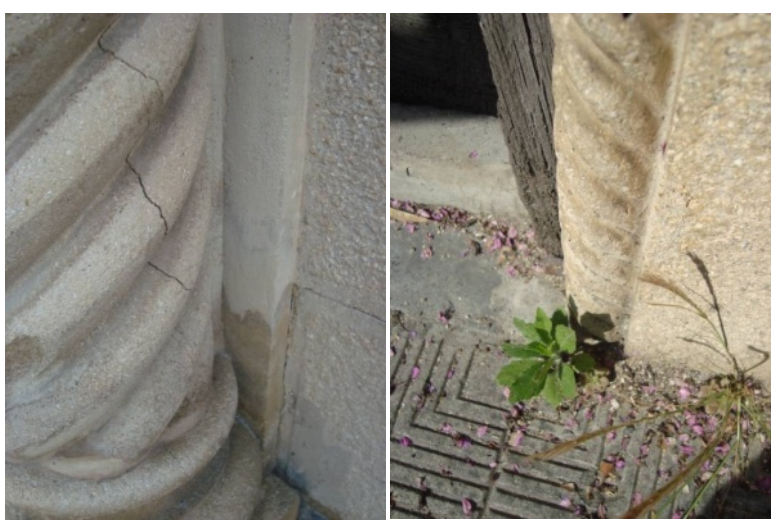

Figure 9. photos of Erosion

\section{Limitations}

There are some crucial setbacks to the diagnosis phase of this project these includes;

1) Resourcing of plan materials and tests equipments was not possible due to time limitations and authority consent.

2) Only diagnosis survey subjected to visual and observation and with non destructive tests are provided here. No other detail survey done on moisture or humidity conditions, ventilations, insulation for internal external temperatures, soil and structural footing tests.

\section{Conclusion}

One, of the fresh and cured composite repairmortar formulations, the ultimate goal of this testing program was to attainmortar formulations of optimal workability, durability, and compatibility. The tests included in this research are by 
no meansexhaustive in the investigation of mortar behavior; however, they address thecritical performance properties generally identified for mortar materials. These properties include: consistency, setting time, drying shrinkage, thermal expansion, hydric expansion, water vapor transmission, water absorption, flexural strength and modulus of elasticity, salt crystallization resistance, and frost resistance. The tests were conducted on samples of mortar without sandstone attached.

Restoration is a continuous process, so is learning, we as restorers needs to keep learning, how to diagnose as well as conserve buildings, the building is in a damaged form, there is a immediate need of conservation in order to stop or retard the process of deterioration.

\section{REFERENCES}

[1] CONGRESS ON THE EUROPEAN ARCHITECTURAL HERITAGE 21 - 25 October 1975 The Declaration of Amsterdam
[2] European Charter of the Architectural Heritage Adopted by the Council of Europe, October 1975

[3] The Athens Charter for the Restoration of Historic Monuments Adopted at the First International Congress of Architects and Technicians of Historic Monuments, Athens 1931

[4] Lectures of Assistant Professor ABDUL QADIR BHATTI Scholar EMDiReB 2009 SCEE NUST, Islamabad bhatti-nit@nust.edu.pk

[5] Lectures of Assistant Professor NataliyaLushnikova Scholar EMDiReB 2009 National University of Water Management and Natural Resourced use Department of Building Elements Technology and Material Science Rivne Ukraine

[6] UNESCO World Heritage Centre

[7] International Council on Monuments and Sites

[8] The International Scientific Committee on the Analysis and Restoration of Structures of Architectural Heritage

[9] "Art conservation and restoration." Encyclopædia Britannica. 2010. Encyclopædia Britannica Online. 29 Apr. 2010<http://www.britannica.com/EBchecked/topic/36477/ar t-conservation-and-restoration 